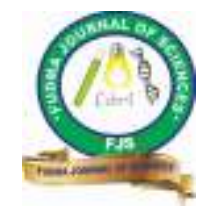

FUDMA Journal of Sciences (FJS)

ISSN online: $2616-1370$

ISSN print: 2645 - 2944

Vol. 4 No. 2, June, 2020, pp 46 - 52

DOI: https://doi.orq/10.33003/fis-2020-0402-149

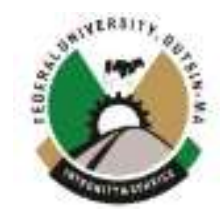

\title{
INFRARED THERMOGRAPHIC INSPECTION OF ELECTRICAL JUNCTIONS IN SOME ELECTRICITY DISTRIBUTION FACILITIES IN AHMADU BELLO UNIVERSITY
}

\author{
Abdelmalik, A. A., Muhammed, M. I., Muhammad, A. B., Ismaila, A. and Aliyu, A. \\ Department of Physics, Ahmadu Bello University, Zaria, Nigeria. \\ *Corresponding author's email: aaabdelmalik@abu.edu.ng
}

\begin{abstract}
Electrical or insulation failure is usually accompanied by two major events among others; production of acoustic pulses (sound) and an increase in temperature owing to heating. These lead to costly energy dissipation. Distribution boards are elementary necessities in any electrical wiring but overheating at the junctions can result in serious energy loss and eventual fire outbreak. There are several methods and techniques used in monitoring and assessing the state of power equipment and components in the electricity network. One of such techniques is Infrared thermography (IRT). An average temperature of $92.4^{\circ} \mathrm{C}$ and $33.7^{\circ} \mathrm{C}$ were recorded on the three-phase distribution board for the building during the peak and off-peak periods respectively. The inspection of the distribution boards in the Physics Department building of Ahmadu Bello University, Zaria, using thermal imaging camera, revealed excessive heating at the three-phase distribution board during peak hours, leading to Ohmic loss. The dissipated energy during the peak period ranges from 665 $\mathrm{W} / \mathrm{m}^{2}$ to $1.5 \mathrm{~kW} / \mathrm{m}^{2}$. The heating resulted in an average energy loss of about $1 \mathrm{~kW} / \mathrm{m}^{2}$. The energy loss at the junctions may have, among other factors, contributed to the high electricity billing at the university.
\end{abstract}

Keywords: Infrared thermography, thermal image camera, electric power equipment, insulation failure, diagnostics

\section{INTRODUCTION}

There was a serious outcry in the year 2018 over high electricity billing of Ahmadu Bello University, Zaria which the community and stakeholders seem not to believe. The questions then are; what is responsible for the high consumption of electricity in the university? Could it be that a substantial amount of the electricity bill may have been due to distribution losses? Unfortunately, there is no available monitoring system to assess the amount of energy loss during the distribution of electricity within the university from the $33 / 13 \mathrm{kV}$ substation to the endusers. Several methods and techniques such as Dissolved Gas Analysis (DGA), Partial discharge detection, are used in monitoring and assessing the state of power equipment and components in the electricity network and one such technique is Infrared thermography (IRT) (Khan et al., 2016). This technique involves a non-destructive test method and non-contact mapping of the spatial distribution of heat and measurement of temperature. It detects, records and displays thermal patterns and temperature across the surface of an object (Bagavathiappan et al., 2013). It utilizes an infrared camera and uses a real-time thermal imaging system for temperature measurement and analysis of both dynamic and static thermal patterns. The core value of thermography lies in its being able to identify that a thermal anomaly exists (Lisowska-lis, 2017).

While thermography can identify a connection problem through thermal pattern analysis, the connector surface temperature can be a very poor indicator of the nature of the problem or its severity. Infrared thermography is, therefore, an effective condition monitoring (CM) technique that rapidly, accurately and safely detects problems, before failure, as indicated by thermal anomalies (Jadin et al., 2011).

An electrical or insulation failure is accompanied by two major events among others; production of acoustic pulses (sound) and an increase in temperature owing to heating. These will lead to energy dissipation (Petrosyants, 2012). Many events lead to such heat production and these localized areas are popularly known as hot spots or partial discharges in equipment insulation. These hot spots may glow as the object warms up, emitting radiation in form of light. The amount of radiation emitted by an object increases with temperature, therefore thermography allows one to see variations in temperature with time or load. The radiated energy in the form of photons is based on temperature and emissivity of the material. Infrared radiation is electromagnetic radiation, similar to light and radio waves. Wavelengths of light between 2-15 microns are called thermal infrared radiation (Petrosyants, 2012). In poorly connected electric cables in a low voltage line, these hot spots may lead to fire accidents.

The thermal radiation emitted can be explained using blackbody radiation. A blackbody is defined as an imaginary object which absorbs all incident energies and emits a constant spectrum. The emitting power of a black body per unit area and unit solid angle for a particular wavelength, $\left(\mathrm{W}_{\lambda \mathrm{b}}\right)$ can be calculated using the 
Planck's law (Usementiaga et el., 2005) as shown in the equation below:

$$
\mathrm{W} \lambda \mathrm{b}=\frac{C 1 \lambda^{-5}}{\exp (C 2 / \lambda T)-1}
$$

Where $C_{1}$ and $C_{2}$ are constants, $\lambda$ is the wavelength and $T$ is the temperature. The wavelength at which electromagnetic radiation is emitted depends on the temperature of the object. The higher the temperature the shorter the wavelength. The peak wavelength for a specific temperature value can be calculated using Wien's Law:

$$
\lambda_{\text {peak }}=\frac{0.0029}{T}
$$

Material's ability to emit thermal radiation is called emissivity. Each material has a different emissivity which may vary with temperature and infrared wavelength. To make an accurate thermal measurement of an object using an infrared camera, it is necessary to estimate or determine the object's emissivity. Modern thermal imaging cameras are designed with an inbuilt emissivity value for some known materials. This is denoted with $\varepsilon$. The rate of energy emission per emitting surface area, $\mathrm{W}_{\mathrm{b}}$ $\left(\mathrm{W} / \mathrm{m}^{2}\right)$ is expressed as:

$$
W_{b}=\frac{q}{A}=\varepsilon \sigma T^{4}
$$

Temperature measurement using infrared thermography (IRT) measures the infrared radiation emitted by an object and converts the energy into a temperature value. However, since not all the radiation received comes from the target object, radiation from other sources (such as surrounding objects from the atmosphere) must be removed in the conversion to temperature. This process is called compensation (Usementiaga et el., 2005). There are two ways of temperature measurement in infrared thermography. It can be quantitative, which takes the exact temperature of objects. It can be qualitative, which takes the relative temperature value of hotspot with respect to other parts of the equipment under the same operating conditions.

Electrical systems and components have been monitored using Infrared thermography. In a survey conducted on a power system using infrared thermography, conductor connection accessories and bolted connections were found to have constituted $48 \%$ of the problems. This was due to loose connections, corrosion, rust and inadequate use of inhibitory grease. On the other hand, disconnection contacts were found to have constituted $45 \%$ of thermal anomalies. These were due to deformations, deficient pressure of contact, incorrect alignment of arms and dirt. Just about $7 \%$ of the problems were attributed to electrical equipment (Titman, 2001). About a decade ago, the electrical switchgear of the ACME Widget Company was inspected using an Infrared thermography technique and its MSR/MAIN panel was found to have been damaged due to overload (Hopkins, 2011). Infrared thermography system was developed by Petrosyants for control and monitoring, energysaving and safety in a piece of electrical heating equipment for domestic applications. The program was used for a detailed analysis of the temperature of electric components, wiring and elements of the electrical supplies (Petrosyants, 2012). IRISYS (IRI4010) thermal imaging camera was used for condition assessment of power transformers and motors. The IR image of a $110 / 33 \mathrm{KV}$ transformer shows that the upper part of the transformer is hot, while the lower part is cold. This was due to improper circulation of the insulating oil leading to temperature difference (Khan et al., 2016). Thermographic monitoring was performed on some power transformers by examining the temperature distribution on the surface of a single device using FLIR thermal imaging cameras. It was reported that for a transformer whose electrical insulation is in good condition, the lower areas on the surface of the device were cooler. But for a transformer with deteriorated electrical insulation, hot-spots were detected at the top, the middle and lower part of the surface of the device (Lisowska-lis, 2017).

In this work, the thermographic analysis of some feeder pillars and distribution boards was conducted to examine the energy loss at the junctions. This is to know if significant energy is loss at the junction boxes that may have contributed to the high energy cost of the university.

\section{MATERIALS AND METHODS}

Feeder pillars are the breaker panels which are the very first set of switching/protection devices at the output/secondary side a transformer. There is some effective electrical enclosure to provide electrical services for low voltage electrical distribution applications. Their system is designed as compact and robust for vandalism protection. The metal enclosure is made of steel sheet (minimum of $2 \mathrm{~mm}$ thickness) mounted on a steel base frame (minimum of $3 \mathrm{~mm}$ thickness) suitable for outdoor application. The feeder pillars between the department of Geology and faculty of Arts, Area A (site 1), Area BZ and Kashim Ibrahim Library, all in Ahmadu Bello University, Zaria were utilized. All the distribution boards in the Department of Physics, Ahmadu Bello University Zaria, Nigeria were also used for this study. UNI-T UTi80 thermal imager (Figure 1) was used for the measurements. It can detect temperature variations of an area through a 2.4 inch LCD. It has a temperature range of $-30^{\circ} \mathrm{C} \sim$ $400^{\circ}$ and basic accuracy of $\pm 3.5^{\circ} \mathrm{C}$ for measurements below $0^{\circ} \mathrm{C}$ and $\pm 2^{\circ} \mathrm{C}$ for measurements above $0^{\circ} \mathrm{C}$.

Thermographic inspections were performed on the hotspot phases of Area A (site 1), Area BZ, faculty of Art/Geology department and Kashim Ibrahim (KIL) feeder pillars in September 2019. While the feeder pillars at Area A and Area $\mathrm{BZ}$ are serving residential quarters, the feeder pillars at KIL and between the department Geology and faculty of Art serve the academic area on the main campus of Ahmadu Bello University Zaria, Nigeria. 


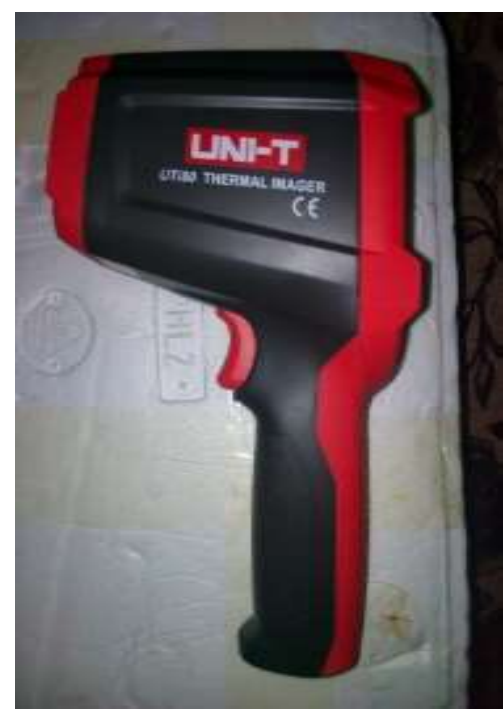

Figure 1. UTi80 Thermal Image

The camera was switched-on ten minutes before the operation to allow for sensor stabilization. The temperature was determined using the camera's dual laser which can quickly lock in the measurement area and display target temperature. The emissivity of the material was set using reference materials' emissivity. To inspect the feeder pillars, the cover of the feeder pillars was removed as the direct view is required in IR thermography. At a distance of $2 \mathrm{~m}$ between the target and the camera, the surface temperature was measured by focusing the laser of the camera on the feeder pillars, shots were taken along a straight and perpendicular path to the target to avoid view angle effect on temperature reading. The measurement was done twice in a day at around $12 \mathrm{pm}$ and $5 \mathrm{pm}$. The inspection was performed during the period of maximum possible loading (peak hour) and the period of possible minimum loading (off- peak). For the distribution boards' inspection, circuit loading of the distribution board was taken into account before performing the inspection. The covering of the distribution board was also removed to enable direct view/imaging. Several shots were taken using the same procedure described for feeder pillars.

Thermographic inspection of four distribution boards in the three floors of the department of Physics building was performed. The building receives electricity supply from the transformer installed close to the department of Chemistry via a three-phase distribution board, which is the main distribution board, with each floor having a distribution board that feeds offices and laboratories. Measurements were taken in the afternoon within $12 \mathrm{pm}$ and $1 \mathrm{pm}$ when the department was assumed to be on its possible maximum loading (peak hour) and in the evening during the possible minimum loading (off-peak). The heat energy radiated from the distribution boards was calculated using Stefan's radiation law.

\section{RESULTS AND DISCUSSIONS}

Figure 2 shows the photo of the feeder pillar and the corresponding thermal image.

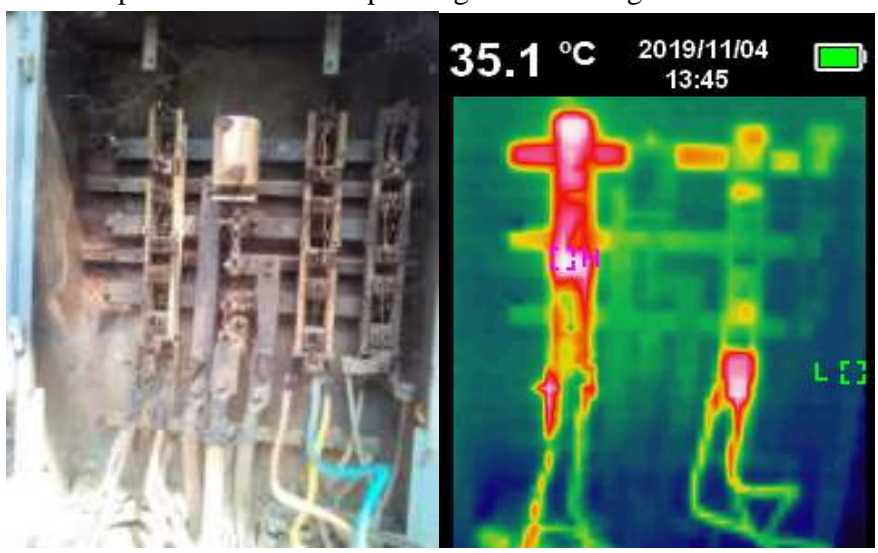

Figure 2: Thermal image of feeder pillar showing the hotspots. 
Figure 3 shows the bar chats of the thermographic inspection of the feeder pillars. Figures $3 \mathrm{a}$ and $3 \mathrm{~b}$ show the temperatures of the detected hotspots of the loaded phase at $12 \mathrm{pm}$ and $5 \mathrm{pm}$ and the corresponding energy dissipated in the form of heat is shown in $3 \mathrm{c}$ and $3 \mathrm{~d}$ respectively. The feeder pillars were observed to be in normal condition as the hotspot temperatures are below $40^{\circ} \mathrm{C}$, which is within the acceptable limit. The presented heat loss (energy dissipated) in bar chat was calculated using Stefan's Boltzmann law. The dissipated energy at the feeder pillars serving residential areas around $5 \mathrm{pm}$ is slightly higher than that by noon. This is likely due to an increase in load at the residential area after work hours. The dissipated energy was found to be between $355 \mathrm{~W} / \mathrm{m}^{2}$ and $422 \mathrm{~W} / \mathrm{m}^{2}$. Meanwhile, the dissipated energy at the feeder pillars serving the academic areas is higher around noon when compared to that around $5 \mathrm{pm}$. This may likely be due to a reduction in load.

Figure 4 shows a picture of the thermal image of the main distribution board. Figure 4(a) shows the picture of the threephase distribution board that supplied electricity to the three floors of the department while 4(b) shows the thermal image of the hotspot of the distribution board with hotspot temperature of $133^{\circ} \mathrm{C}$.

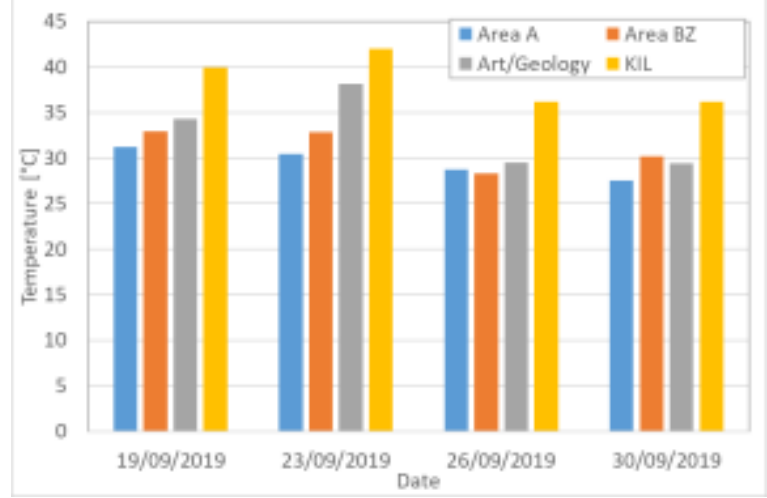

a: Hotspot temperature at 12 noon

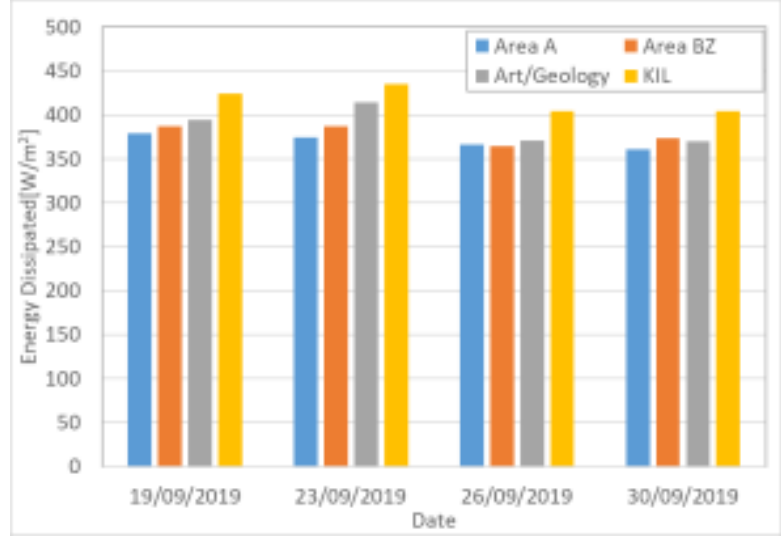

c: Energy Dissipate at 12 noon

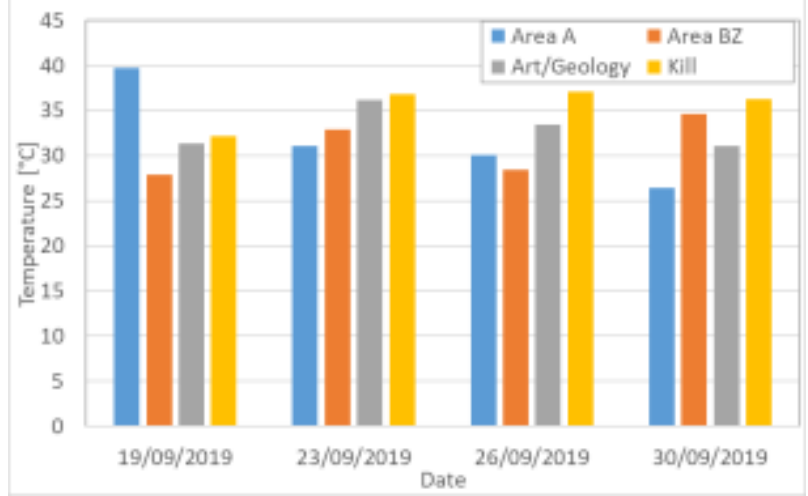

b: Hotspot temperature at $5 \mathrm{pm}$

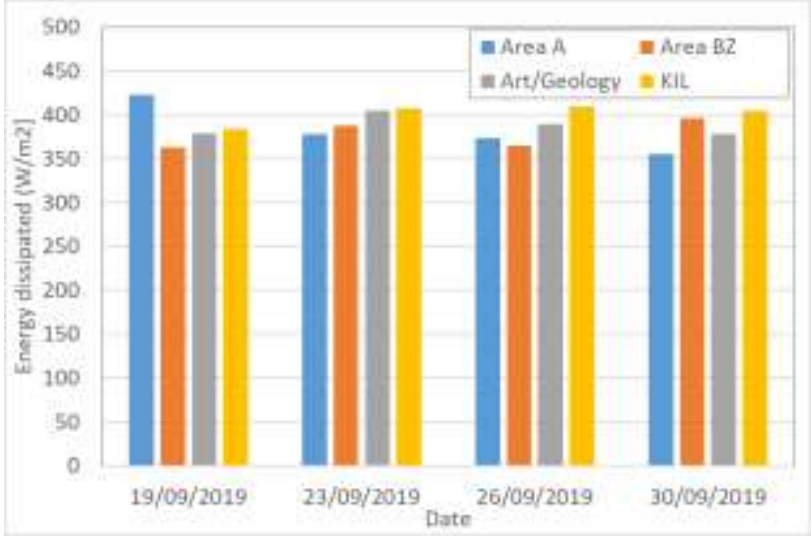

$\mathrm{d}$ : Energy dissipated at $5 \mathrm{pm}$

Figure 3: Thermographic inspection of feeder pillars

Figure 5 shows the bar chat of thermal readings of the distribution board during the assumed periods of possible maximum and minimum loading respectively. A large difference was observed between the measurements taken during work and after work hours. The mean temperature of the distribution board for the building after work hours was determined to be $33.7^{\circ} \mathrm{C}$. With this temperature, the $\mathrm{DB}$ is considered to be in the normal operation mode. On the other hand, the temperature of up to $133^{\circ} \mathrm{C}$ was recorded from the DB. The temperature of $35.7^{\circ} \mathrm{C}$ that was recorded during the period designated as peak period was measured around 4:00 pm just after the electricity supply was restored (having seized for some hours on that particular day). On the three-phase distribution board for the building, an average temperature of $92.4^{\circ} \mathrm{C}$ and $33.7^{\circ} \mathrm{C}$ were recorded during the peak and off-peak periods respectively. This heat energy generated in the electrical junctions of the distribution board stems up from the conversion of charge carriers of a conductor to thermal energy during the passage of electric current. 

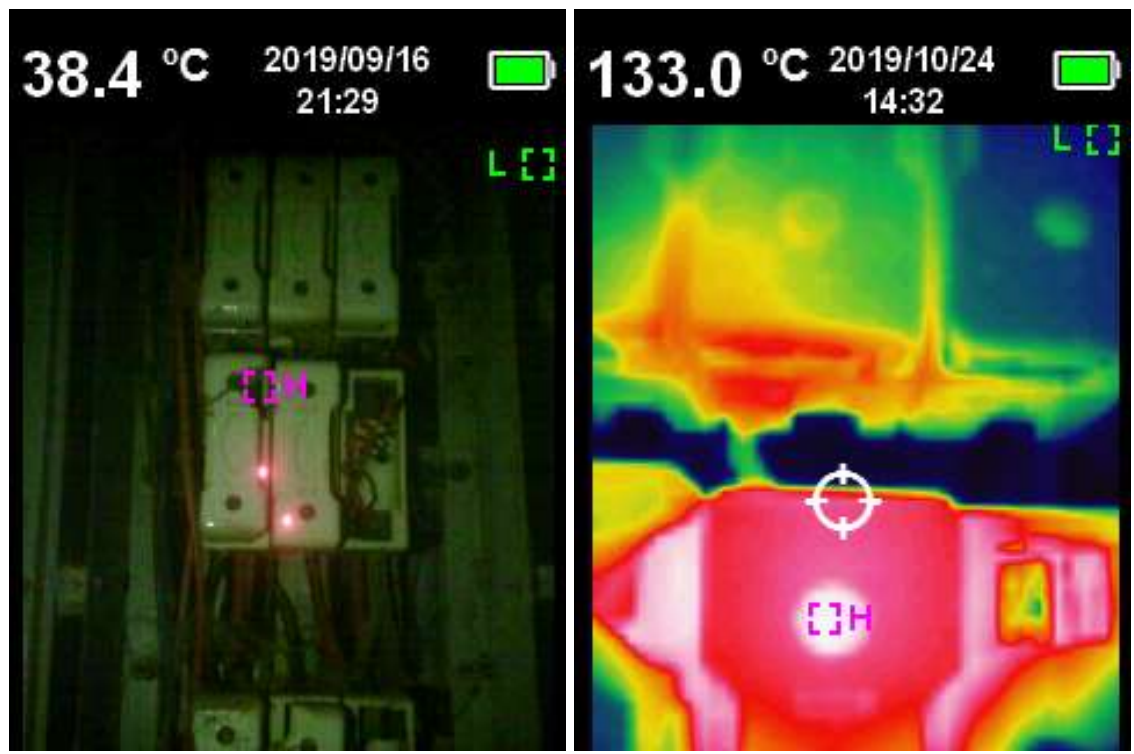

Figure: 4 (a) three-phase distribution board, (b) thermal image of the main distribution board

Figure 6 shows the bar chat of energy dissipated at the distribution board during the assumed period of maximum and minimum positive loading respectively. The energy dissipated at the distribution board after work hours is relatively stable with a mean value of $477 \mathrm{~W} / \mathrm{m}^{2}$. The dissipated energy during the peak period ranges from $665 \mathrm{~W} / \mathrm{m}^{2}$ to $1.5 \mathrm{~kW} / \mathrm{m}^{2}$. The average energy dissipated as heat during the period studied was evaluated to be $1 \mathrm{~kW} / \mathrm{m}^{2}$.

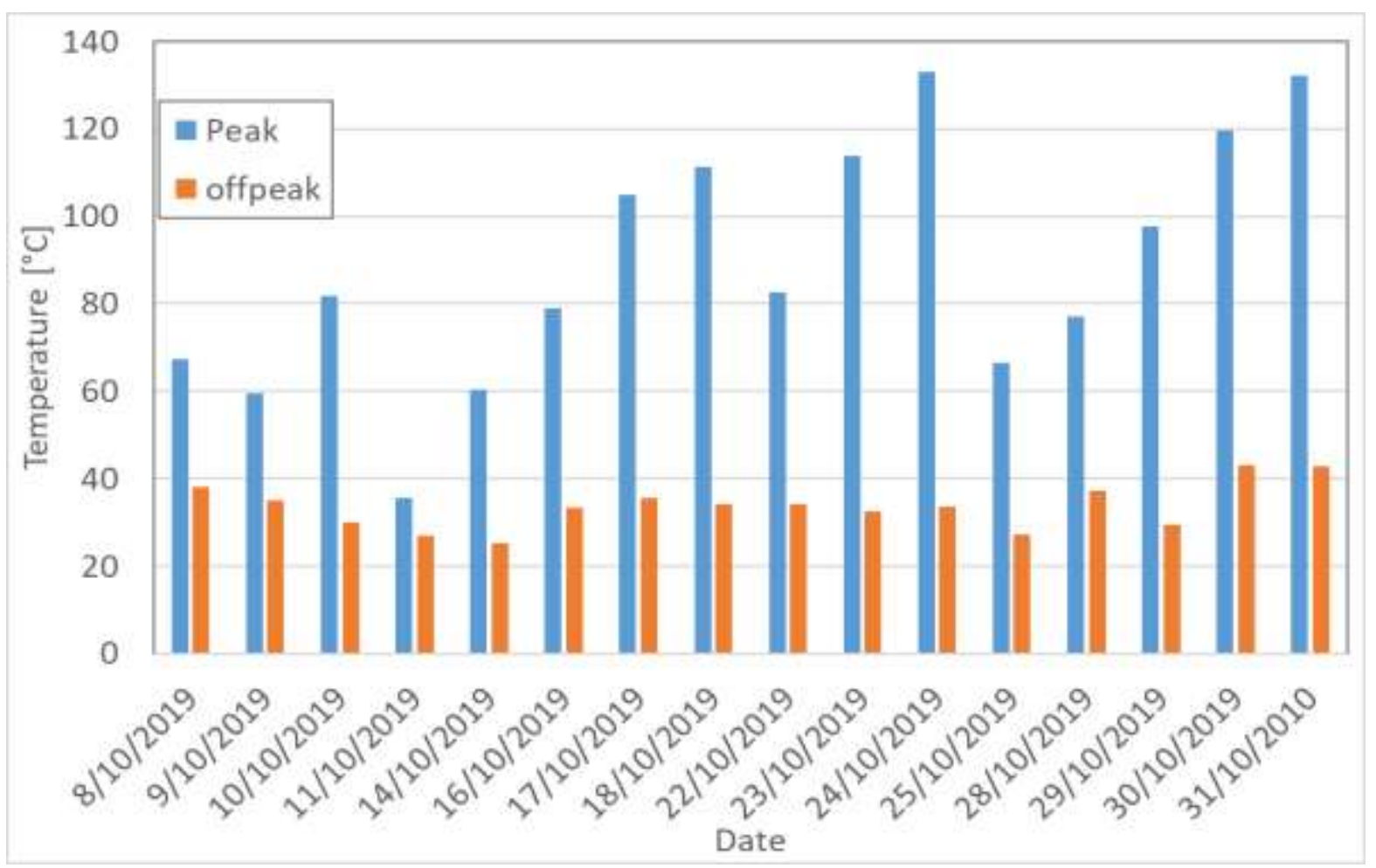

Figure 5: Hotspot temperature of the three-phase distribution board 


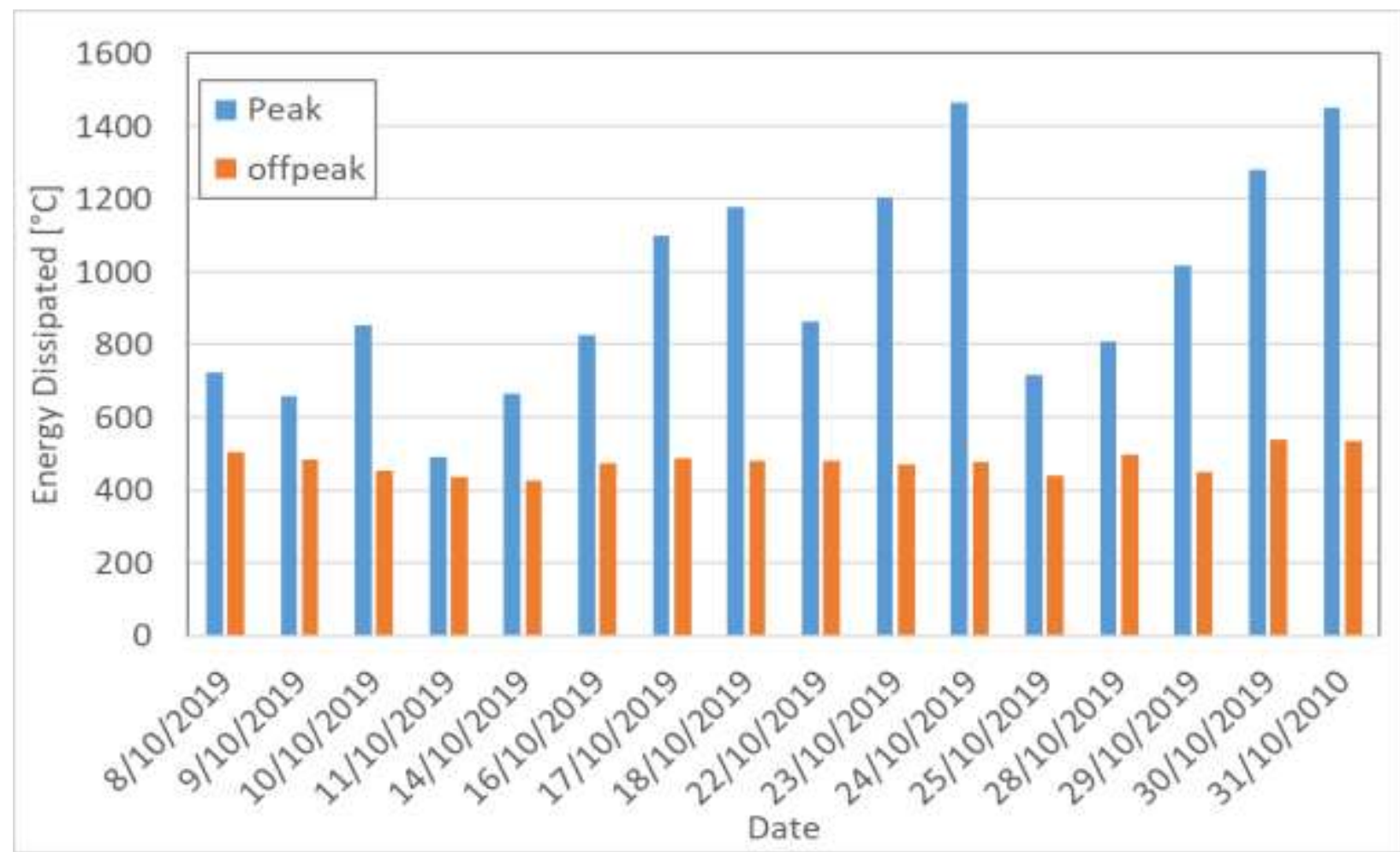

Figure 6: Energy dissipated at the three-phase distribution board

Thermographic inspection of the distribution boards on each floor of the building was also performed. The inspection was routinely done over 3 weeks. An average temperature of $27.4^{\circ} \mathrm{C}$ and $25.6^{\circ} \mathrm{C}$ was recorded from the $\mathrm{DB}$ on floor 1 during the peak and off-peak period respectively. That amounts to an average energy loss of about $438.7 \mathrm{~W} / \mathrm{m}^{2}$ at the junction during peak period. An average temperature of $32.6^{\circ} \mathrm{C}$ and $25.8^{\circ} \mathrm{C}$ was recorded from the DB on floor 2 during the peak and off-peak periods respectively. This also amounts to an average energy loss of about $471.1 \mathrm{~W} / \mathrm{m}^{2}$ at the junction during peak period. An average temperature of $26.9^{\circ} \mathrm{C}$ and $25.5^{\circ} \mathrm{C}$ was recorded from the $\mathrm{DB}$ on floor 3 during the peak and off-peak period respectively. That amounts to an average energy loss of about $435.9 \mathrm{~W} / \mathrm{m}^{2}$ at the junction during peak period. The temperature of the operating system of an electrical system is rated to be between $40^{\circ} \mathrm{C}$ and $50^{\circ} \mathrm{C}$. Temperature above this value is considered to be overheating. This indicates the operation of DBs at each floor is on normal mode and no overheating phenomenon is recorded at the electrical junctions at the peak periods. Meanwhile, the overheating phenomenon is recorded at the three-phase distribution board. This overheating could be caused by any overload or faulty connection in the network as observed in the distribution board located on the first floor where the neutral lines were terminated.

These results reveal that overheating leads to energy loss. $1 \mathrm{~kW}$ energy loss per square meter shows that if the cumulative surface that is involved in overheating is up to one square meter in the physics building, that will amount to 1 unit of energy loss for every hour of the peak period. The classification of the condition of the distribution boards based on Delta-T criterion indicates that the distribution boards studied has $\Delta \mathrm{T}$ values of $59^{\circ} \mathrm{C}, 1.4^{\circ} \mathrm{C}, 6.8^{\circ} \mathrm{C}$ and $1.8^{\circ} \mathrm{C}$ for the three-phase, floor 1 , floor 2 and floor 3 DBs respectively (Khan et al., 2016). This placed the three-phase distribution board components on priority 1. Objects on priority 1 require immediate corrective measures following NETA (NETA, 2001). Priority table suggested that thermography inspection can detect faults responsible for the creation of hotspots and reduce fault clearance time and energy loss.

\section{CONCLUSION}

IR thermography is becoming a significant monitoring tool in all industrial applications. It assists operators and site engineers to monitor the state of the power utility, detect a malfunction to foretell any potential failures and suggest corrective measures. This prevents sudden failure, reduces capital loss and guarantees the safety of appliances. Distribution boards are elementary necessities in any electrical wiring. Overheating at the junction box results in severe energy loss and can lead to fire outbreaks. Inspection of the three-phase distribution boards in the Physics department building of Ahmadu Bello University revealed excessive heating during working hours. The heating resulted in a loss of energy of about $1 \mathrm{~kW} / \mathrm{m}^{2}$. The faults at these junctions that resulted in high energy loss, among other things, may have 
significantly contributed to the high electricity bill of the university.

\section{REFERENCES}

Khan, Q., Khan, A.A., \& Ahmad, F. (2016). Condition Monitoring Tool for Electrical Equipment - Thermography, International Conference on Electrical, Electronics, and Optimization Techniques (ICEEOT) - 2016. DOI: 10.1109/ICEEOT.2016.7755208

Bagavathiappan, B., Lahiri, B.B., Saravanan, T., Philip, J., \& Jayakumar, T. (2013). Infrared thermography for condition monitoring - A review, Infrared Physics \& Technology, 60, 3555 .

Lisowska-lis, A., (2017). Thermographic monitoring of the power transformers, Measurement Automation Monitoring, 4(63), 154-157.

Jadin, M.S., Taib, S., Kabir, S. (2011). Infrared thermography for assessing and monitoring electrical components within concrete structures, Progress in Electromagnetics Research, 787.

Petrosyants, I., (2012). IR thermography system for control and monitoring of energy saving and safety in heating and electrical equipment of housing services, 11th International Conference on Quantitative InfraRed Thermography, 11-14 June 2012, Naples Italy.
Usementiaga, R., Venegas, P., Guerediaga, J., Vega, L., Molleda, J., \& Bulnes, F.G. (2014). Infrared thermography for temperature measurement and non-destructive testing, Sensor, 12310.

Usamentiaga, R., Gracia, D., Lopez, C., \& Gonzalez, J. (2005). Algorithm for real time acquisition and segmentation of a stream of thermographic line scans in Industrial Environment, Journal of imaging science Technology, 138-153.

Titman, D.J., (2001). Application of thermography in nondestructive testing of structures, NDT\&E International, 34(2), 149-154.

Hopkins, P., (2011). Qualitative Infrared thermographic survey of electrical switchgear, SoCal Infrared Thermal imaging services. www.studylib.net, assessed 18/01/2020.

NETA MTS-2001, (2001). Maintenance testing specification for electrical power distribution equipment and systems, InterNational Electrical Testing Association. 